\title{
Diagnostic Value of Ultrasound and Tc-99m MIBI scintigraphy and SPECT/CT for Pre-operative Localization of Parathyroid Adenoma in Patients with Primary Hyperparathyroidism: A Single-Center Comparative Study
}

\author{
Bülent Çolakoğlu1 (1), Deniz Alış2 \\ ${ }^{1}$ Clinic of Radiology, Vehbi Koç Foundation American Hospital, İstanbul, Turkey \\ 2Department of Radiology, İstanbul Mehmet Akif Ersoy Thoracic and Cardiovascular Surgery Training and Research Hospital, İstanbul, Turkey
}

Cite this article as: Çolakoğlu B, Alış D. Diagnostic Value of Ultrasound and Tc-99m MIBI scintigraphy and SPECT/CT for Pre-operative Localization of Parathyroid Adenoma in Patients with Primary Hyperparathyroidism: A Single-Center Comparative Study. JAREM 2019; 9(3): 115-20.

\begin{abstract}
Objective: To assess and compare the diagnostic ability of ultrasound (US) and 99 mTc-MIBI planar scintigraphy in a combination with singlephoton-emission computed tomography/computed tomography (SPECT/CT) for the pre-operative evaluation of primary hyperparathyroidism.

Methods: We retrospectively reviewed 60 patients who underwent parathyroidectomy for primary hyperparathyroidism. All patients had to undergo pre-operative Tc-99m MIBI planar scintigraphy+SPECT/CT and US examinations to be included in the study. All US examinations were performed by the single experienced operator. The diagnostic accuracy of the imaging methods was assessed by using the surgical pathology as a reference method.

Results: Surgical pathology revealed solitary parathyroid adenoma in 54 patients and multiglandular disease in five patients (hyperplasia in four patients and adenoma in one patient). The sensitivity and the diagnostic accuracy of US in detecting solitary adenoma were $88.9 \%$ and $87.2 \%$, respectively, while the sensitivity and the diagnostic accuracy of Tc- $99 \mathrm{~m} \mathrm{MIBI}$ planar scintigraphy+SPECT/CT were $96.3 \%$ and $94.5 \%$, respectively. However, the combination of the two methods was able to detect all solitary adenomas. The overall diagnostic accuracy of US, Tc-99m MIBI planar scintigraphy+SPECT/CT, and the combination of the modalities for solitary lesions and multiglandular disease were $86.6 \%, 90 \%$, and $96.6 \%$, respectively.

Conclusion: The US and Tc-99m MIBI planar scintigraphy+SPECT/CT had an excellent diagnostic ability in assessing patients with primary hyperparathyroidism in the pre-operative period; however, the combination of these methods showed even a more superior diagnostic accuracy and sensitivity, reaching up to $96.6 \%$ and 98.3 , respectively. We highlight that the combination of these two methods should always be preferred in the pre-operative assessment of parathyroid adenoma.
\end{abstract}

Keywords: Hyperparathyroidism, parathyroid adenoma, parathyroid hyperplasia, ultrasound, TC-99m MIBI-sestamibi, scintigraphy, SPECT/CT

\section{INTRODUCTION}

Hyperparathyroidism is defined as an increased level of parathyroid hormone and can be classified as primary, secondary, and tertiary hyperparathyroidism. Over functioning of the gland itself due to adenoma or hyperplasia is classified as primary hyperparathyroidism (PHPT), and approximately $80 \%$ of PHPT cases occurs due to parathyroid adenomas (1). Although PHPT typically involves the musculoskeletal system, particularly bones, the disease can manifest with diverse clinical symptoms and findings, including peptic ulceration, alterations in the mental status, and nephrolithiasis (1, 2). Traditionally, conventional bilateral neck exploration was the method of choice for the operation, but there has been a recent trend toward minimally invasive parathyroidectomy (MIP), mostly given the technological advancements of the pre-operative imaging methods (3-6). The success of MIP has been endorsed by many studies, showing that while MIP has comparable curative rates with the traditional approaches, it also offers lower complication rates, reduced costs, substantially shorter operation and post-operative hospitalization time, and better cosmetic results (4-6).

Conventional ultrasound (US) and $99 \mathrm{mTC}-\mathrm{MIBI}$ scintigraphy are the most widely used modalities in the pre-operative evaluation of the patients with suspicion of PHPT secondary to parathyroid disease. To date, many studies have investigated and favored the diagnostic value of these two methods in detecting parathyroid adenomas, although a considerably wide range of sensitivity has been reported (7-11). 
Herein, we aimed to assess and compare the diagnostic value of pre-operative US and 99 mTc-MIBI planar scintigraphy in combination with single-photon-emission computed tomography/ computed tomography (SPECT/CT) for the pre-operative evaluation of PHPT.

\section{METHODS}

A local ethics committee approved this retrospective study, which was carried out from January 2006 to January 2018. A need of informed consent was waived by the ethic board for the retrospective review of the clinical and radiologic data of patients. A total of 60 patients with clinically and biochemically proven PHPT (increased intact PTH, increased serum calcium, and normal kidney functions) were included in the study. All patients had to have a pre-operative US and $99 \mathrm{mTc}-\mathrm{MIBI}+\mathrm{SPECT} / \mathrm{CT}$ scan to be eligible for the study. Patients with recurrent or persistent hyperparathyroidism, a history of former thyroid or parathyroid operation, and a history of any neck malignancy were excluded from the study.

\section{$99 \mathrm{mTc}-\mathrm{MIBI}+\mathrm{SPECT} / \mathrm{CT}$ and US examinations}

Dual-phase parathyroid scintigraphy using the $99 \mathrm{mTc}-\mathrm{MIBI}$ was utilized for all patients. First, $740 \mathrm{MBq}$ of $99 \mathrm{mTc}-\mathrm{MIBI}$ were given to patients, and then immediate (at 10 minutes) and delayed (at 180 minutes) images were obtained. The immediate phase comprised static images of the chest on the anterior plane at $10 \mathrm{~min}$ utes, and static images of the neck on the anterior, left and right, and left oblique planes at 5 minutes after the injection. All acquisitions were handled using a low-energy, high-resolution parallelhole collimator with a matrix size $256 \times 256$ and a $1.85 \times$ zoom level. Afterward, static anterior left and right oblique plane images were obtained from a distance of $10 \mathrm{~cm}$ from the patient's skin using a five pinhole collimator $\mathrm{mm}$ in diameter (matrix size, 256x256; 2.19x zoom). A dual-head gamma camera (Siemens) that was adjusted to $140 \mathrm{keV}$ and had a $10 \%$ width (range, 133-147 keV) was used for all planar imaging. Approximately 1 hour after the $99 \mathrm{mTc}-\mathrm{Ml}$ $\mathrm{BI}$ administration, the neck and the upper thorax of the patients were examined with a SPECT/CT (SIEMENS INTEVO 6 xSPECT) equipped with a dual-head gamma camera (matrix size, 128x128), which was combined with the CT system positioned on the same gantry. The CT system parameters were $2.5 \mathrm{~mA}$ and $130 \mathrm{kVp}, 2 \times 2.5$ $\mathrm{mm}$ collimation, and $10 \mathrm{~mm}$ sections reconstructed in a $256 \times 256$ matrix. The delayed images consisted of the same acquisitions as for the immediate phase 5 min pinhole and parallel hole images.

Two discriminative features of parathyroid adenomas were used when interpreting scintigraphy examinations: 1) Both thyroid parenchyma and parathyroid adenomas show the $99 \mathrm{mTc}-\mathrm{MIBI}$ uptake during the early phases; however, normal thyroid gland showed faster wash-out compared to the adenomas, while adenomas showed fixed 99 mTc-MIBI uptake during the later phases; and 2) occasionally, parathyroid adenomas might also show more prominent tracer uptake during the early phases (12). Figure 1 shows a $99 \mathrm{mTc}$ MIBI planar scintigraphy+SPECT/CT image of a patient with adenoma.

The same observer with over 20 years of thyroid and parathyroid ultrasound experience performed all US examinations. The patients were directed to lay in a comfortable supine position, hyperextending their necks for the US evaluation. The operator performed all examinations with the same device (LOGIQ E9 with XDclear, General Electric (GE) Healthcare, Wauwatosa, WI, USA) using a linear array transducer (ML6-15) with a frequency range 12-15 MHz. The observer examined the neck putting a particular focus on posterior neighborhoods of the upper and the lower parts of the thyroid lobes. Given the more diverse presentation of the lower quadrant adenomas, the observer delicately explored the paratracheal regions, the area around the carotid artery, and deep regions of the neck and superior mediastinum using the oblique craniocaudal view. The observer identified parathyroid adenomas by their oval-shaped, solid, and hypoechogenic appearance compared to thyroid parenchyma. In equivocal cases, a Doppler US was also applied to identify the feeder artery, which commonly stems from the inferior thyroid artery and giving it an arc- or rim-like vascular appearance (10). The observer noted whether the adenoma was present, and if present, the exact location of the lesion, as located in the right-upper, right-lower, left-upper, and left-lower pole of the parathyroid gland. Moreover, if more than one lesion was detected, the observer also noted that lesion. The incidental or previously known pathologies of

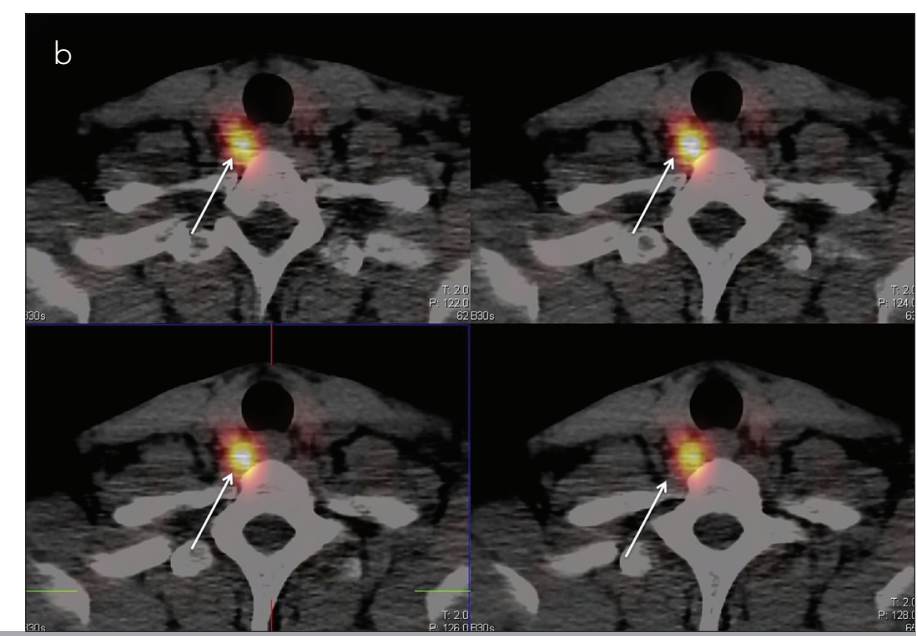

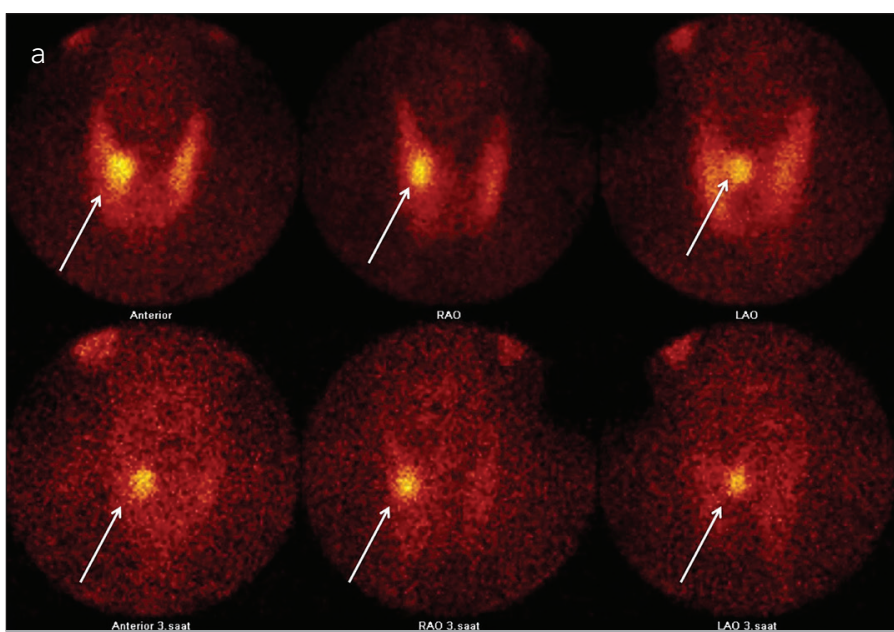

Figure 1. a, b. Tc-99 m MIBI dual-phase planar (a) and SPECT/CT (b) images of a patient with a 13x8 mm parathyroid adenoma (arrows) located on the right lower quadrant of the gland. Please note that the images are ordered from left to right and up to bottom as representing early through the late phases of the examination 


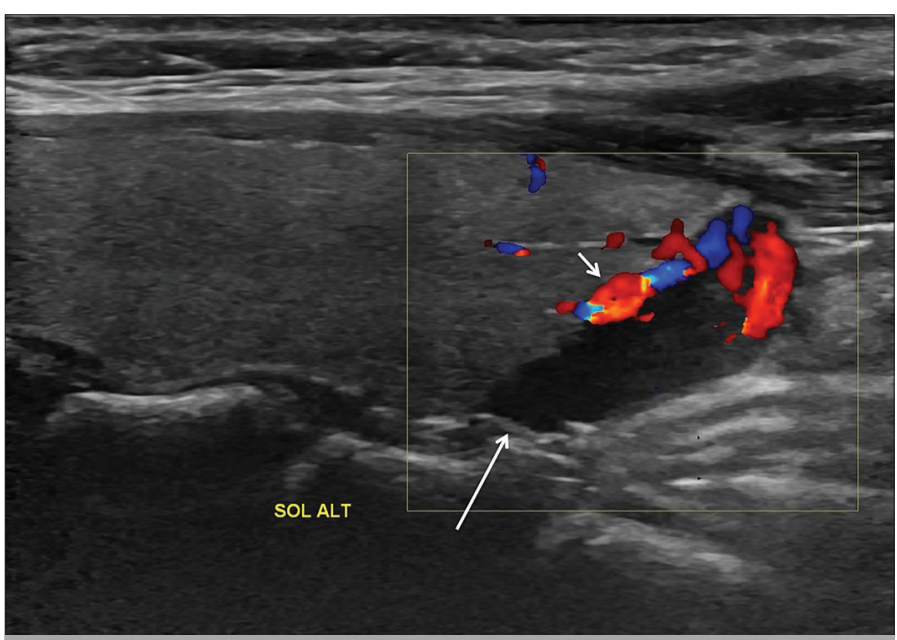

Figure 2. US image of a patient with a parathyroid adenoma located on the left lower quadrant of the gland (arrow). The lesion is hypoechogenic with well-defined borders showing a characteristic extrathyroidal feeding vessel (short arrow)

the thyroid gland that were identified during the examination were also indicated for a further diagnostic workup.

\section{Surgery}

All the procedures were performed under general anesthesia. Patients with solitary parathyroid adenoma and without additional thyroid pathology were operated by one of the three surgeons in our institute using minimal invasive parathyroidectomy in light of the pre-operative US and $99 \mathrm{mTc}$-MIBI planar scintigraphy+SPECT/ CT. The surgeons applied total or unilateral thyroidectomy operation with a more extensive surgical approach in appropriate cases. The adenoma location according to US and scintigraphy findings was presented as four quadrants: the right-upper, right-lower, leftupper, and left-lower quadrant. The surgeons started the operation by placing an approximately $2-3 \mathrm{~cm}$ transverse incision line over the proper localization of the adenoma. To prevent damage, the recurrent laryngeal nerve was carefully monitored during the procedure. If a thyroid operation was necessary or the disease was multiglandular, a total thyroidectomy with a more extensive neck exploration was performed rather than MIP. The success of the operation was determined by measuring the intraoperative intact parathyroid hormone levels in which the reduction of the PTH $<50 \%$ was accepted as an adequate removal. All of the patients were discharged within 2 days after the operation, and no significant complications were encountered.

\section{Statistical Analysis}

All statistical analyses were performed using the Statistical Package for Social Sciences 21 version (IBM Corp.; Armonk, NY, USA). All continuous variables were presented as the mean standard deviation unless otherwise specified. Pre- and post-operative PTH, Ca, and p levels were compared using the paired Student's t-test. The sensitivity, specificity, and diagnostic accuracy of the US and $99 \mathrm{mTc}-\mathrm{MIBI}$ scintigraphy were calculated accepting the surgical pathology as a reference method for both per lesions. The true positive (TP) result was defined as correct identification of the parathyroid adenoma side and the level (i.e., if the imaging study identified a lesion in the right-upper quadrant of the disease and the surgery confirmed the presence, then the diag- nosis was classified as TP). If the pre-operative imaging correctly assessed the side but incorrectly interpreted the level, that case was accepted as the false negative (FN). False-positive results were defined as a pre-operative positive lesion in the relevant location despite negative surgical findings. The following formulas were used the calculate sensitivity, TP/(TP+FN); specificity, TN/ $(\mathrm{TN}+\mathrm{FP})$; and diagnostic accuracy, $(\mathrm{TP}+\mathrm{TN}) /(\mathrm{TP}+\mathrm{TN}+\mathrm{FP}+\mathrm{FN})$.

\section{RESULTS}

A total of 60 patients, 9 male (15\%) and 51 female (85\%), with a mean age of $54.78+12.80$ years were enrolled in the study. Detailed demographics, and pre- and post-operative biochemical and histological findings of the patients are listed in Table 1. Among 60 patients, 54 had solitary parathyroid adenoma (90\%), while five patients (8.3\%) had a multiglandular disease, and all of them were hyperplasia. All patients with solitary parathyroid adenoma underwent MIP, except for patients who had a combination of thyroidectomy and parathyroidectomy during the same session. Pre-operative US identified 48/54 (88.9\%) of the solitary adenoma, while pre-operative 99 mTcMIBI planar scintigraphy +SPECT/CT was able to identify all solitary adenomas except for two patients (96.3\%). The solitary adenoma missed by the scintigraphy was detected on the pre-operative US. Hence, the combination of pre-operative US and 99 mTc-MIBI planar scintigraphy+SPECT/CT correctly identified all the solitary parathyroid adenomas. Among five patients with multiglandular disease, one had right upper and lower, one had right lower and left upper, two had right lower and left lower, and one had a four-quadrant disease. US was able to identify all multiglandular involvements in four out of five patients (80\%) except for the patients with glandular hyperplasia involving all quadrants of the gland. Among these five patients, 4 had parathyroid hyperplasia, and one had two parathyroid adenomas. US was able to correctly identify two out of four of these glandular involvements, yet given to our methodology, this case was accepted as FN. The $99 \mathrm{mTc}-\mathrm{MIBI}$ planar scintigraphy+SPECT/CT detected the pathology in three out of five patients (60\%) with multiglandular disease. The $99 \mathrm{mTc}-\mathrm{MIBI}$ planar scintigraphy+SPECT/CT also could not detect all quadrants in patients with multiglandular disease involving all quadrants and entirely missed the pathology in the other patient. In one patient, both the US and 99 mTc-MIBI planar scintigraphy identified a solitary nodule in the right parathyroid gland, yet surgical exploration could not detect abnormal parathyroid tissue. This patient was scheduled for a follow-up after the operation. Table 2 demonstrates the sensitivity and diagnostic accuracy of the US, $99 \mathrm{mTc}-\mathrm{MIBI}$ planar scintigraphy+SPECT/CT, and a combination of these modalities for solitary parathyroid adenoma; Table 3 shows findings of the imaging modalities and the final results of the pathological specimen for multiglandular disease; and Table 4 shows an overall sensitivity and diagnostic accuracy of the US and 99 mTc-MIBI planar scintigraphy+SPECT/CT in detecting parathyroid pathology.

\section{DISCUSSION}

In the present study, we demonstrated that while the $99 \mathrm{mTc}$ MIBI planar scintigraphy+SPECT/CT had a slightly better sensitivity (91.5\% vs. $88.1 \%$ ) and diagnostic accuracy (90\% vs. $86.6 \%)$ compared to US in identifying parathyroid pathology in patients with PHPT, both of the methods showed sufficient success in accurately determining the location of the pathology. Furthermore, a combination of these methods provided an even better diag- 
Table 1. Demographics, clinical characteristics, pre- and post-operative biochemical findings of the study cohort

\begin{tabular}{|c|c|c|}
\hline Variables & Findings & $\mathrm{p}$ \\
\hline Age & $57.78+12.80(26-86)$ & - \\
\hline Gender & & - \\
\hline Female & $51(85 \%)$ & \\
\hline Male & $9(15 \%)$ & \\
\hline Pre-operative Ca (mg/dL) & $11.08+0.95(8.6-13.6)$ & $<0.0001$ \\
\hline Post-operative Ca (mg/dL) & $9.14+0.79(7.6-11.2)$ & \\
\hline **Pre-operative PTH (pmol/l) & $136(76.75)$ & $<0.0001$ \\
\hline **Post-operative PTH (pmol/l) & $26(14.8)$ & \\
\hline Pre-operative $\mathrm{P}(\mathrm{mg} / \mathrm{dL})$ & $2.70+0.52(1.9-4.2)$ & NS \\
\hline Pre-operative $\mathrm{P}$ (mg/dL) & $2.71+0.52(1.9-4)$ & \\
\hline Multiglandular disease & & - \\
\hline Yes & $5(8.3 \%)$ & \\
\hline No & 55 (91.7\%) & \\
\hline Ectopic Parathyroid Adenoma & & - \\
\hline Yes & $2(3.3 \%)$ & \\
\hline No & 58 (96.7\%) & \\
\hline \multicolumn{3}{|l|}{ Thyroid pathology } \\
\hline Present & $\begin{array}{c}19(31.7 \%), 13 \text { Nodular } \\
\text { goiter }(68.4 \%), 6 \text { Papillary } \\
\text { carcinoma (31.6\%) }\end{array}$ & - \\
\hline Absent & 41 (68.3\%) & \\
\hline $\begin{array}{l}\text { Average weight of the } \\
\text { surgical specimen (mg) }\end{array}$ & $574.9+329.94(114-2160)$ & - \\
\hline \multicolumn{3}{|l|}{ Location of the adenoma } \\
\hline Right upper quadrant & $4(7.2 \%)$ & \\
\hline Right lower quadrant & $21(38.1 \%)$ & \\
\hline Left upper quadrant & $8(14.5 \%)$ & \\
\hline Left lower quadrant & $22(36.7 \%)$ & \\
\hline
\end{tabular}

Table 2. Sensitivity and diagnostic accuracy of imaging methods in detecting solitary parathyroid adenoma

\begin{tabular}{|l|c|c|}
\hline Modalitiy & Sensitivity & $\begin{array}{c}\text { Diagnostic } \\
\text { accuracy }\end{array}$ \\
\hline Ultrasound & $88.9 \%$ & $87.2 \%$ \\
\hline $99 \mathrm{mTC} \mathrm{MIBI+SPECT/CT}$ & $96.3 \%$ & $94.5 \%$ \\
\hline $\begin{array}{l}99 \mathrm{mTC} \mathrm{MIBI}+\mathrm{SPECT} / \mathrm{CT} \\
\text { combination with US }\end{array}$ & $100 \%$ & $98.1 \%$ \\
\hline $\begin{array}{l}\text { *US=ultrasound, } 99 \mathrm{mTC} \text { MIBI+ SPECT/CT=Technetium-99m sestamibi in } \\
\text { combination single photon-emission computed tomography/computed } \\
\text { tomography }\end{array}$ \\
\hline
\end{tabular}

nostic value (diagnostic accuracy $96.6 \%$ and sensitivity $98.3 \%$ ) for the pre-operative evaluation of the parathyroid lesions.

Ultrasound (US) and $99 \mathrm{mTc}-\mathrm{MIBI}$ planar scintigraphy are the standard imaging methods for the pre-operative assessment in the patients with PPTH. In the past century, pre-operative utilization of these modalities was deemed unnecessary for the evaluation of parathyroid adenoma since the primary approach to parathyroid adenoma involved a bilateral conventional surgical exploration of the neck $(3,13)$. However, the main trend in the surgical approach for parathyroid adenomas has shifted toward minimally invasive procedures substantially depending on the pre-operative imaging studies (4-6). Many studies have explored the diagnostic value and the role of the US, 99 mTc-MIBI planar scintigraphy, and also the $99 \mathrm{mTc}-\mathrm{MIBI}$ planar scintigraphy+SPECT/CT in the pre-operative investigations of the patient with PHPT.

The reported sensitivity of US has considerably varied among the studies. In the present study, the overall sensitivity of US was $88.1 \%$, which was favorably comparable to most of the previous reports with a reported sensitivity range 44\%-90\% (14-21). We suggest that several factors might have led to this wide gap between the studies. First, US is considerably an operator-dependent modality; hence, the experience of the operator seems to be a one of the critical factors resulting in this difference $(20,22)$. Second, the previous works were conducted within a substantially long timeline; therefore, the technological advancements of the US units might also play an essential role in this issue (14-21).

Furthermore, the location of the parathyroid adenomas might also lead to this difference. It has been well-known that ectopic locations such as the upper mediastinum and the retroesophageal area, or deep location of the adenoma, pose particular challenges for the sonographic evaluation $(23,24)$. In our study, only two of the 59 patients with surgically proven parathyroid pathology had adenomas located in the upper mediastinum, and US failed to detect both of these lesions, in line with the several previous works $(4,23,24)$.

Besides from the evaluation of the parathyroid lesions, US also had several advantages over the $99 \mathrm{mTc}-\mathrm{MIBI}$ planar scintigraphy+SPECT/CT. First, US has a better spatial resolution, which allowed the operator to investigate potential thyroid pathology simultaneously, and this advantage might be quite helpful in endemic areas for thyroid disease (25). For instance, $31.7 \%$ of the patients in our study cohort underwent total or unilateral thyroidectomy in combination with parathyroid surgery for their additional thyroid pathology. As in conjunction with the several previous works, US showed a better diagnostic performance in multiglandular disease compared to scintigraphy, and correctly detected all the pathological quadrants in four out of five of the patients (80\%) (25-27). US is also a costeffective, portable, non-radiation-bearing modality with widespread availability compared to scintigraphy. Moreover, US also could increase the confidence of the surgeons by confirming scintigraphic findings and, hence, aid surgeons tailoring the best surgical strategy for MIP.

Despite US advantages, the $99 \mathrm{mTc}-\mathrm{MIBI}$ planar scintigraphy is commonly accepted as the gold standard modality for the preoperative evaluation of patients with PHPT (12). The reported sensitivity and diagnostic accuracy of the $99 \mathrm{mTc}-\mathrm{MIBI}$ planar scintigraphy was substantially higher compared to US in the pre- 
Table 3. US, 99mTc MIBI+ SPECT/CT, and surgical pathology findings of patients with multiglandular disease

\begin{tabular}{|l|l|c|c|}
\hline Patients & Ultrasound & $99 m T c$ MIBI+ SPECT/CT & Histopathology \\
\hline 1 & LLQ+ RLQ & LLQ & RUQ+ RLQ+ LUQ+LLQ (Hyperplasia) \\
\hline 2 & LLQ+LUQ & - & LLQ+LUQ (Hyperplasia) \\
\hline 3 & LLQ+LUQ & LLQ+LUQ & LLQ+LUQ (Hyperplasia) \\
\hline 4 & RLQ+LUQ & RLQ+LUQ & RLQ+LUQ (Hyperplasia) \\
\hline 5 & RUQ+RLQ & RUQ+RLQ & RUQ+RLQ (adenoma) \\
\hline RUQ: Right upper quadrant; RLQ: right lower quadrant; LUQ: left upper quadrant; LLQ: left lower quadrant & \\
\hline
\end{tabular}

Table 4. Overall sensitivity and diagnostic accuracy of imaging methods in detecting parathyroid disease

\begin{tabular}{l|c|c|}
\hline Modalitiy & Sensitivity & Diagnostic accuracy \\
\hline Ultrasound & $88.1 \%$ & $86.6 \%$ \\
\hline $99 m T c \mathrm{MIBI}+\mathrm{SPECT/CT}$ & $91.5 \%$ & $90 \%$ \\
\hline $\begin{array}{l}99 \mathrm{mTC} \mathrm{MIBI}+\mathrm{SPECT} / \mathrm{CT} \\
\text { combination with US }\end{array}$ & $98.3 \%$ & $96.6 \%$ \\
\hline $\begin{array}{l}\text { *US=ultrasound, 99mTc MIBI+ SPECT/CT=Technetium-99m sestamibi in } \\
\text { combination single photon-emission computed tomography/computed } \\
\text { tomography }\end{array}$ \\
\hline
\end{tabular}

vious works (25-28). The $99 \mathrm{mTc}$ MIBI planar scintigraphy is also superior to US in detecting ectopic lesions, and in our study, the $99 \mathrm{mTc}-\mathrm{MIBI}$ planar scintigraphy+SPECT/CT was able to show two ectopic parathyroid adenomas, where US failed to do so. One of the main disadvantages of the 99 mTc-MIBI planar scintigraphy is its lower spatial and anatomical resolution compared to US, which is currently substantially alleviated by the addition of SPECT/CT to the planar imaging (30). In our study, we did not compare planar imaging with the cross-sectional method, yet the reported diagnostic accuracy of SPECT/CT was higher in previous works (30). In the present work, the main flaw of the $99 \mathrm{mTc}$ MIBI planar scintigraphy+SPECT/CT was exposed by multiglandular disease in conjunction with the previous reports (25-27). Several authors advocated that dominant increased function of one of the pathological glands in multiglandular disease might reduce the reached tracer to the others, which substantially limits the detection of the glands. Increased expression of a multidrug resistance protein, glycoprotein $\mathrm{P}$, is also considered to limit the $\mathrm{MIBI}$ uptake in these patients. P-glycoprotein is coded by the multidrug resistance gene located at the 7 th chromosome and results in increased wash-out of the $\operatorname{MIBI}(30,31)$.

There were several limitations to our study. First, the study was retrospectively designed; hence, our findings should be evaluated with precaution. Second, we did not compare SPECT/CT with the planar imaging, as mentioned in the previous paragraphs. Third, we had only two patients with ectopic parathyroid adenoma and five patients with multiglandular disease, which substantially limited us to draw a definite conclusion concerning the diagnostic value of the US and $99 \mathrm{mTc}-\mathrm{MIBI}$ planar scintigraphy+SPECT/ $\mathrm{CT}$ in these patients. Finally, we did not investigate the ability of imaging methods to detect pathology compared to adenomas weight.

\section{CONCLUSION}

Ultrasound (US), in the hands of a skilled and experienced operator, and the $99 \mathrm{mTC}-\mathrm{MIBI}$ planar scintigraphy+SPECT/CT had separately an excellent diagnostic ability in assessing patients with PHPT in the pre-operative period; however, the combination of these methods showed an even superior diagnostic accuracy and sensitivity reaching up to $96.6 \%$ and 98.3 , respectively. We highlight that although both of these methods could be separately used as a pre-operative guide for the MIP, their combination should always be preferred.

Acknowledgment: We acknowledge to Professor Dr. Mehmet Onur Demirkol for review and criticism in improving the manuscript and also sharing his invaluable experience and knowledge regarding the nuclear imaging methods used in the study.

Ethics Committee Approval: Ethics committee approval was received for this study from the Ethics Committee of Vehbi Koç American Hospital.

Informed Consent: Informed consent was not taken from patients due to the retrospective nature of the study.

Peer-review: Externally peer-reviewed.

Author Contributions: Concept - B.Ç.; Design - B.Ç.; Supervision - B.Ç.; Resources - B.Ç.; Data Collection and/or Processing - D.A.; Analysis and/ or Interpretation - D.A.; Literature Search - D.A.; Writing Manuscript B.Ç., D.A.; Critical Review - B.Ç.

Conflict of Interest: The authors have no conflict of interest to declare.

Financial Disclosure: The authors declared that this study has received no financial support.

\section{REFERENCES}

1. Potts JT. Diseases of the parathyroid gland and other hyper- and hypocalcemic disorders. In: Braunwald E, Isselbacher KJ, Petersdorf RG, Wilson JD, Martin JB, Fauci AS, eds. Harrison's Principles of Internal Medicine, 11th edn. New York: McGraw Hill, 1987; p.18701889.

2. Fraser WD. Hyperparathyroidism. Lancet 2009; 374: 145-58. [CrossRef]

3. Satava RM, Beahrs OH, Scholz DA. Success rate of cervical exploration for hyperparathyroidism. Arch Surg 1975; 110: 625-8 [CrossRef]

4. Smit PC, Rinkes IHM, van Dalen A, van Vroonhoven TJMV. Direct, minimally invasive adenomectomy for primary hyperparathyroidism. An alternative to conven- tional neck exploration? Ann Surg 2000; 231: 559-65. [CrossRef]

5. Ulanovski D, Feinmesser R, Cohen M, Sulkes J, Dudkiewicz M, Shpitzer T. Preoperative evaluation of patients with parathyroid adenoma: role of high resolution ultrasonography. Head Neck Surg 2002; 24: 1-5. [CrossRef] 
6. Udelsman R. Six hundred fifty-six consecutive explorations for primary hyperparathyroidism. Ann Surg 2002; 235: 665-70. [CrossRef]

7. Nichols KJ, Tomas MB, Tronco GG, Rini JN, Kunjummen BD, Heller KS, et al. Preoperative parathyroid scintigraphic lesion localization: accuracy of various types of readings. Radiology 2008; 248: 221-32. [CrossRef]

8. Elaraj DM, Sippel RS, Lindsay S, Sansano I, Duh QY, Clark OH, et al. Are additional localization studies and referral indicated for patients with primary hyperparathyroidism who have negative sestamibi scan results? Arch Surg 2010; 145:578-81. [CrossRef]

9. Berber E, Parikh RT, Ballem N, Garner CN, Milas M, Siperstein AE. Factors contributing to negative parathyroid localization: an analysis of 1000 patients. Surgery 2008; 144: 74-9. [CrossRef]

10. Johnson NA, Tublin ME, Ogilvie JB. Parathyroid imaging: technique and role in the preoperative evaluation of primary hyperparathyroidism. AJR Am J Roentgenol 2007; 188: 1706-15. [CrossRef]

11. Kim, Yl, Jung YH, Hwang KT, Lee HY. Efficacy of 99m Tc-sestamibi SPECT/CT for minimally invasive parathyroidectomy: comparative study with 99m Tc-sestamibi scintigraphy, SPECT, US and CT. Ann Nucl Med 2012; 26: 804-10. [CrossRef]

12. Hindié E, Ugur Ö, Fuster D, ODoherty M, Grassetto G, et al. EANM parathyroid guidelines. Eur J Nucl Med Mol Imaging 2009; 36: 1201 16. [CrossRef]

13. van Heerden JA, Grant CS. Surgical treatment of primary hyperparathyroidism: an institutional perspective. World J Surg 199; 15: 688-92. [CrossRef]

14. Chapuis $Y$, Fulla $Y$, Bonnichon $P$, Tarla E, Abboud B, et al. Values of ultrasonography, sestamibi scintigraphy, and intraoperative measurement of 1-84 PTH for unilateral neck exploration of primary hyperparathyroidism. World J Surg 1996; 20: 835-40. [CrossRef]

15. Mazzeo S, Caramella D, Lencioni R, Molea N, De Liperi, A, et al. Comparison among sonography, double- tracer subtraction scintigraphy, and double-phase scintigraphy in the detection of parathyroid lesions. AJR Am J Roentgenol 1996; 166: 1465-70. [CrossRef]

16. Geatti O, Shapiro B, Orsolon PG, Proto G, Guerra UP, Antonucci F, et al. Localization of parathyroid enlargement: experience with technetium-99m methoxyisobutyl- isonitrile and thallium-201 scintigraphy ultrasonography and com- puted tomography. Eur J Nucl Med 1994; 21: 17-22. [CrossRef]

17. Hindie E, Melliere D, Simon D, Perlemuter L, Galle P. Primary hyperparathyroidism: is technetium $99 \mathrm{~m}$-sestamibi/iodine-123 subtraction scanning the best procedure to locate enlarged para- thyroid glands before surgery? J Clin Endocrinol Metab 1995; 80: 302-7. [CrossRef]

18. Bonjer HJ, Bruining HA, Valkema R, Lameris JS, de Herder WW, van der Harst $E$, et al. Single radionuclide scintigraphy with 99mtechnetium-sestamibi and ultrasonography in hyperparathyroidism. Eur $\mathrm{J}$ Surg 1997; 163: 27-32.

19. Staudenherz A, Abela C, Niederle B, Steiner E, Helbich T, Puig S, et al. Comparison and histopathological correlation of three para- thyroid imaging method in a population with a high prevalence of concomitant thyroid disease. Eur J Nucl Med 1997; 24: 143-9. [CrossRef]

20. De Feo ML, Colagrande S, Biagini C, Tonarelli A, Bisi G, Vaggelli L, et al. Parathyroid glands: combination of $(99 \mathrm{~m})$ Tc MIBI scintigraphy and US for demonstration of parathyroid glands and nodules. Radiology 2000; 214: 393-402. [CrossRef]

21. Tunca F, Akic, M, Işcan Y, Cem IS, Giles YS, Terzioğlu T. The impact of combined interpretation of localization studies on image-guided surgical approaches for primary hyperparathyroidism. Minerva Endocrinol 2017; 42: 213-22.

22. Lloyd MN, Lees WR, Milroy EJ. Preoperative localization in primary hyperparathyroidism. Clin Radiol 1990; 41: 239-43. [CrossRef]

23. van Dalen $A$, Smit CP, van Vroonhoven TJ, Burger $H$, de Lange EE. Minimally invasive surgery for solitary parathyroid adenomas in patients with primary hyperparathyroidism.

24. Gilat H, Cohen M, Feinmesser R, Benzion J, Shvero J, Segal K, et al. Minimally invasive procedure for resection of a parathyroid adenoma: the role of preoperative high-resolution ultrasonography. $J$ Clin Ultrasound 2005; 33: 283-7. [CrossRef]

25. Alexandrides TK, Kouloubi K, Vagenakis AG, Yarmenitis S, Spyridonidis $T$, Vassilakos $P$, et al. The value of scintigraphy and ultrasonography in the preoperative localization of parathyroid glands in patients with primary hyperparathyroidism and concomitant thyroid disease. Hormones (Athens) 2006; 5: 42-51. [CrossRef]

26. Xue J, Liu Y, Ji T, Zhao A, Liang Y, Deng H, et al. Comparison between technetium-99m methoxyisobutylisonitrile scintigraphy and ultrasound in the diagnosis of parathyroid adenoma and parathyroid hyperplasia. Nucl Med Commun 2018; 39: 1129-37. [CrossRef]

27. Wakamatsu H, Noguchi S, Yamashita H, Yamashita H, Tamura S, Jinnouchi $S$, et al. Technetium-99m tetrofosmin for parathyroid scintigraphy: a direct comparison with 99m Tc-MIBI, 201 TI, MRI and US. Eur J Nucl Med 2001; 28: 1817-27. [CrossRef]

28. Akbaba G, Berker D, Isik S, Aydin Y, Ciliz D, Peksoy I, et al. A comparative study of pre-operative imaging methods in patients with primary hyperparathyroidism: ultrasonography, 99mTc sestamibi, single photon emission computed tomography, and magnetic resonance imaging. J Endocrinol Invest 2012; 35: 359-64.

29. Treglia G, Sadeghi R, Schalin-Jäntti C, Caldarella C, Ceriani L, et al. Detection rate of $99 \mathrm{mTc}-\mathrm{MIBI}$ single photon emission computed tomography (SPECT)/CT in preoperative planning for patients with primary hyperparathyroidism: A meta-analysis. Head Neck 2016; 38 2159-72. [CrossRef]

30. Alenezi SA, Asa'ad SM, Elgazzar AH. Scintigraphic parathyroid imaging: Concepts and new developments. Res Rep Nucl Med 2015; 5 9-18.

31. Palestro CB, Tomas MB, Tronco GG. Radionuclide imaging of the parathyroid glands. Semin Nucl Med 2005; 35: 266-76. [CrossRef] 